\title{
Runway performance following shifts in drive and reward magnitude '
}

\author{
LINDA GRAGG AND ROGER W. BLACK \\ UNIVERSITY OF SOUTH CAROLINA
}

Rats were trained in a runway under food deprivation with either one or 10 food pellets as reward. All Ss were then tested under relative food satiation and reward magnitude was reversed for half the $S s$ in both groups. No D by $K$ interaction was observed. During satiation, Ss for which rewards were reversed showed large reductions in running speed, while nonreversed $S$ s much smaller decrements, although all Ss showed some reduction in both running and eating behavior. These data were interpreted as consistent with Spence's interpretation of incentive motivation.

While Hull (1952) assumed that the theoretical variables $D$ and $K$ combine in a multiplicative fashion, Spence (1956) assumed that the combination was additive. Most of the experiments concerned with this problem have supported Spence's view, although Seward and his associates reported an interaction of time of deprivation (Td) and magnitude of reward $(\mathrm{Wg})$ in studies in which "low drive" approached food satiation (e.g., Seward, Shea, \& Davenport, 1960). Black (1965) noted that Spence's position requires that consummatory activity occur before any $\mathrm{K}$ develops and thus, that if Ss are trained under conditions of satiation such that they fail to consume the available incentive, no more $K$ will develop than for $S s$ for which a nominal "reward" is not present. To test this view, Black \& Black (1967) trained rats in a runway under food deprivation with either "large" or "small" Wg. During this food deprived period it was assumed that Ss receiving differential levels of Wg should acquire differential levels of $\mathrm{K}$. Thereafter, both groups were shifted to a condition of relative food satiation and the $D$ by $K$ interaction was tested. Statistically, no such interaction was observed, although conclusions based on this result were rendered somewhat tenuous by the failure to obtain a reliable main effect of Wg. In addition, these Es found that Ss trained and tested with the smaller $\mathrm{Wg}$ performed under satiation at a higher level than Ss which received the larger Wg.

The present study was similar in design and purpose to that of Black \& Black (1967), with two major exceptions. First, the ratio of Wgs was increased in an attempt to produce a significant $\mathrm{Wg}$ effect during acquisition. Second, for half the Ss in each Wg group, a reversal occurred in the $\mathrm{Wg}$ received during testing under relative satiation. Following Black and Black's report that the usual direct relationship between $\mathrm{Wg}$ and performance was not obtained under satiation, these reversals represented an attempt to determine whether shifts in $\mathrm{Wg}$ result in rapid changes in performance under satiation such as those reported under conditions of deprivation (e.g., Crespi, 1942).

Method

The Ss were 36 Sprague-Dawley albino rats, about 100 days old at the beginning of training. The basic apparatus consisted of a 46 in. straight alley painted flat black and equipped with a 10 in. start section and a 12 in. goal box, each of which was separated from the runway by sliding retrace doors. The response measure was early alley running speed recorded photoelectronically over the second 6 in. of the runway.

Ten days prior to the beginning of training the Ss were placed on a daily maintenance schedule consisting of $13 \mathrm{~g}$ of lab chow and ad lib access to water. This schedule was maintained throughout the acquisition (deprivation) phase of the experiment, with a correction being made for the amount of food received by the Ss as reward during runway training.

On Acquisition Days 1 and 2, two trials were administered each day, while on Days 3-14 Ss received four trials per day for a total of 52 acquisition trials. For half the Ss (G1) Wg on these trials was one $45 \mathrm{mg}$ Noyes pellet, while for the remaining Ss (G10) the reward was 10 such pellets. If $S$ did not consume its reward within $3 \mathrm{~min}$ it was removed from the goal box. The intertrial interval was about $10 \mathrm{~min}$.

Following the 14 days of deprivation training (acquisition), five days of testing under relative food satiation were conducted. During this period all Ss had ad lib access to both lab chow and water in their home cages. In addition, Ss were give a $30 \mathrm{~min}$ period of access in their carrying cages to both a large supply of Noyes pellets and a wet mash consisting of ground lab chow, condensed milk, and sugar. This procedure was different from that employed by Black \& Black (1967) who withheld food from their Ss each day until $90 \mathrm{~min}$ prior to testing, at which time wet mash and Noyes pellets were made available. The present procedure was an attempt to insure the development of more complete satiation over the five satiation days.

Four runway trials per day for five days were administered to all Ss under the satiation conditions described above. Half of the Ss which had received a Wg of 10 pellets during acquisition, however, received only one pellet during satiation (G10-1), while half of the Ss which had received one pellet received 10 pellets during satiation (G1-10). The remaining Ss received the same $\mathrm{Wg}$ under satiation that they had 


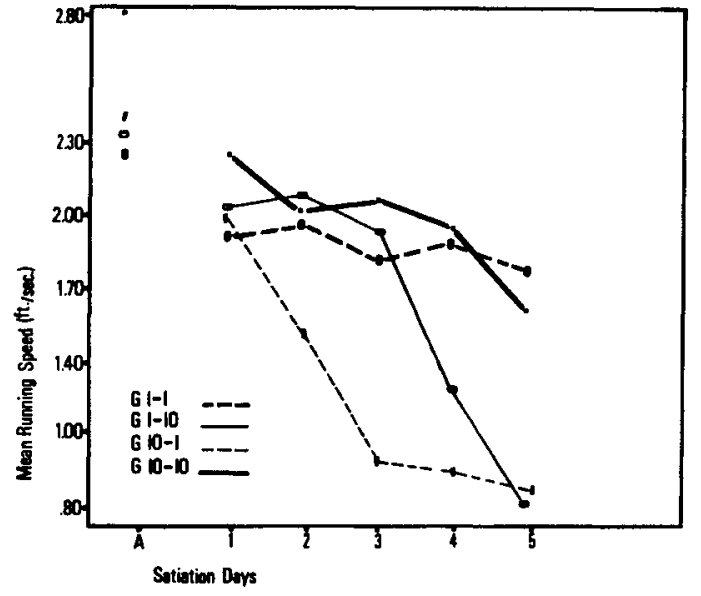

Fig. 1. Mean running speeds tor the four groups on the last day of acquisition $(A)$ and the five days of satiation.

received during acquisition (G1-1 and G10-10). On satiation trials, $S$ was removed from the goal box after it remained there $20 \mathrm{sec}$ or as soon as it had consumed its reward-whichever occurred earlier. On these trials both S's running speed and the number of its avallable pellets consumed were recorded.

\section{Results and Discussion}

Running speeds on the final acquisition day and the flve days of satiation are presented in Fig. 1. An analysis of performance on the last day of acquisition and the first day of satiation for the nonreversed groups (G1-1 and G10-10) indicated a significant effect of Wg $(F=8.38$, df $=1 / 16, p<.05)$ and of drive $(F=8.33$, df $=1 / 16, p<.05)$. The interaction of $D$ and $K$ was, however, not significant $(F=1.80, d f=1 / 16)$. Thus, these results confirmed those of Black \& Black (1967) in suggesting the additive combination of $D$ and $K$ assumed by Spence while, at the same time, demonstrating a significant main effect of $\mathrm{K}$.

A Groups by Days analysis of running speeds for the four groups during the five days of satiation indicated a significant effect of Groups ( $F=6.17$, df $=3 / 32, p<.01)$, Trials $(F=10.86, d f=4 / 124, p<.001)$, and the Groups by Trials interaction $(F=2.11, d f=$ $12 / 124, p<.05)$. Thus, inspection of Fig. 1 indicates that the groups recelving large $\mathrm{Wg}$ during acquisition (G10-10 and G10-1) were initially superior to those Ss which received smaller $\mathrm{Wg}$ in acquisition training. Those groups for which Wg was shifted during satiation (G10-1 and G1-10) showed a much greater $R$ decrement than nonreversed Ss, regardless of the direction of the reversal. In addition, the performance of the nonreversed Ss which received large Wg converged on that of the Ss which received the smaller reward and, in fact, G10-10 was inferior to G1-1 in running speed by the last day of the satiation period. Finally, all groups evidenced some progressive reduction in running speed over the five days of satiation testing.

According to Spence (1956), the magnitude of $K$ was assumed to depend upon the amount or vigor of the consummatory $R\left(R_{G}\right)$. Thus, the general decline in running speeds observed under satiation may have resulted from both a decrement in $\mathrm{D}$ and in the strength of $R_{G}$ during that period. In fact, Ss did show a progressive decline in the amount of their $\mathrm{Wg}$ eaten on trials conducted under satiation in all groups. The rank order correlation between running speed and amount eaten was positive and substantial in G10-10 and G1-1, $\mathrm{r}=.61$ and .56, respectively. This finding was, of course, in agreement with Spence's views. Conversely, while a positive correlation was also obtained for the shifted groups (G10-1 and G1-10), it was quite low, $r=.14$ and .21 , respectively. No explanation of the difference between shifted and nonshifted Ss in this respect or of the much greater running speed decrements exhibited by the shifted groups was immediately apparent to the present writers. It is possible that the shifts in $\mathrm{Wg}$ resulted in generalization decrements assumed to occur following shifts from acquisition to extinction according to the so-called "discrimination hypothesis" (e.g., Mowrer \& Jones, 1945). In any case, these shifts in Wg under satiation conditions did not produce performance changes analogous to the "elation" and "depression" effects reported by Crespi (1942) and others.

\section{References}

Black, R. W. On the combination of drive and incentive motivation. Psychol. Rev., 1965, 72, 310-317.

Black, Patricia E., \& Black, R. W. Interaction of drive and incentive motivation. Psychon. Sci., 1967, 8 ,

Crespi, L. P. Quantitative variation in incentive and performance in the white rat. Amer. J. Psychol., 1942, 55, 467-517.

Hull, C. L. A behavior system. New Haven: Yale University Press, 1952.

Mower, O. H., \& Jones, H. M. Habit strength as a function of pattern of reinforcement. J. exp. Psychol., 1945, 33, 369-386. Spence, K. W. Behavior theory and conditioning. New Haven: Yale University Press, 1956.

\section{Note}

1. This report is based on a thesis submitted by the first author to the Graduate College of the University of South Carolina in partial fulfillment of the requirements for the degree, Master of Arts. 